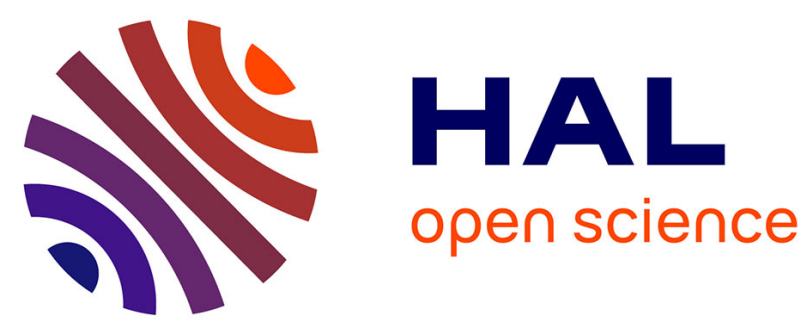

\title{
HEAVY RESIDUE PRODUCTION IN HEAVY ION INDUCED REACTIONS ON 124 Sn BETWEEN 10 AND $84 \mathrm{MeV} / \mathrm{NUCLEON}$
}

\author{
A. Lleres, J. Crançon, J. Blachot, A. Gizon, H. Nifenecker
}

\section{To cite this version:}

A. Lleres, J. Crançon, J. Blachot, A. Gizon, H. Nifenecker. HEAVY RESIDUE PRODUCTION IN HEAVY ION INDUCED REACTIONS ON 124 Sn BETWEEN 10 AND 84 MeV/NUCLEON. International Conference on Heavy Ion Nuclear Collisions in the Fermi Energy Domain,Hicofed 86, 1986, Caen, France. pp.C4-365-C4-368, 10.1051/jphyscol:1986440 . jpa-00225806

\section{HAL Id: jpa-00225806 https://hal.science/jpa-00225806}

Submitted on 1 Jan 1986

HAL is a multi-disciplinary open access archive for the deposit and dissemination of scientific research documents, whether they are published or not. The documents may come from teaching and research institutions in France or abroad, or from public or private research centers.
L'archive ouverte pluridisciplinaire HAL, est destinée au dépôt et à la diffusion de documents scientifiques de niveau recherche, publiés ou non, émanant des établissements d'enseignement et de recherche français ou étrangers, des laboratoires publics ou privés. 


\title{
HEAVY RESIDUE PRODUCTION IN HEAVY ION INDUCED REACTIONS ON 124 Sn BETWEEN 10 AND $84 \mathrm{MeV} /$ NUCLEON
}

\author{
A. LLERES, J. CRANÇON*, J. BLACHOT* , A. GIZON and H. NIFENECKER* \\ Institut des Sciences Nucléaires, IN2P3, 53, Avenue des \\ Martyrs, F-38041 Grenoble, France \\ "CENG/DRF, Service de Physique, Ph.N, BP 85 X, F-38041 Grenoble \\ Cedex, France
}

Résumê 4 - Les spectres en vi tesse des résidus lourds êmis dans les réactions ${ }^{12} \mathrm{C}$, $20 \mathrm{Ne}, 4 \mathrm{O}_{\mathrm{Ar}}+124 \mathrm{Sn}$ ont étế mesurés entre $0^{\circ}$ et $10^{\circ}$, à plusieurs énergies du domaine 10-84 MeV/nucléon. Les données sont en accord avec 1 'hypothèse d'un processus de fusion incomplète asymétrique.

Abstract - Heavy residue velocity spectra of ${ }^{12} \mathrm{C},{ }^{20} \mathrm{Ne}, 40_{\mathrm{Ar}}+{ }^{124} \mathrm{Sn}$ reactions induced in the 10-84 MeV/nucleon energy range have been measured between $0^{\circ}$ and $10^{\circ}$. Asymmetric incomplete fusion process calculations are in agreement with the data.

A limitation of the linear momentum transfer in central heavy ion collisions has been observed in a lot of various experiments performed at intermediate energy $/ 1,3 /$. In other words, the complete fusion process becomes less and less probable as the incident energy increases. To follow progressively the evolution of the more central processes, we have focused our effort on a series of systematic velocity measurements of $124 \mathrm{Sn}$ target-residues recoiling between $0^{\circ}$ and $10^{\circ}$. The aim is to precise, as far as possible, the respective parts of projectile and target participating to the formation of the fused systems which precede the emission of heavy residues.

In this paper, we present in details a set of results on the $20 \mathrm{Ne}+124 \mathrm{Sn}$ system and we apply simple incomplete fusion calculations, in the frame of reasonable assumptions, to reproduce the data at the best. Then, the treatment is extended to mass-velocity spectra observed for other systems as $12 \mathrm{C}+124 \mathrm{Sn}$ or $4 \mathrm{O}_{\mathrm{Ar}}+{ }^{124} \mathrm{Sn}$.

The experiments were performed with various heavy ions, at different energies.

The beams were delivered by several accelerators (ALICE: $10 \mathrm{MeV} /$ nucleon, SARA : 20$30 \mathrm{MeV} /$ nucleon, GANIL : 27-60 MeV/nucleon, SC at CERN : 49 and $84 \mathrm{MeV} /$ nucleon).

The technique was based upon off-line gamma-activity measurements following target irradiations associated with on-1ine collection of reaction products /4/. Heavy residues emitted around the beam axis were collected by a stack of thin aluminium foils ( 1 or $2 \mu \mathrm{m}$ thick) set behind a thin $\left(400 \mu \mathrm{g} \mathrm{x} \mathrm{cm}{ }^{-2}\right.$ ) target, perpendicularly to the beam axis. A collimator placed between the target and the catchers defined a solid angle of $95 \mathrm{msr}\left(\theta=0^{\circ}-10^{\circ}\right)$. The identification of the reaction products with $70 \leqslant A \leqslant 130$ masses was precisely established from the analysis of $\gamma$-ray activity mea surements of all catchers. The velocity distributions were extracted, by use of range tables.

The mass-velocity spectra obtained for residues emitted between $0^{\circ}$ and $10^{\circ}$ in the $20 \mathrm{Ne}+{ }^{124} \mathrm{Sn}$ reaction at $20,30,40$ and $49 \mathrm{MeV} /$ nucleon are shown in figure 1 . on these diagrams, one observes clearly that, at each bombarding energy, the most probable velocity of the residues, $V_{p}$, although relatively high, is lower than the center of mass velocity $V_{\mathrm{cm}}$. This indicates that, for all incident energies, the final products correspond to evaporation residues coming from incomplete fusion mechanisms. Moreover, with increasing incident energy, the difference between $v_{p}$ and $V_{c m}$ increases, indicating that the involved momentum transfer is more and more incomplete. As the residues have been measured between $0^{\circ}$ and $10^{\circ}$, they have been initia- 
ted with parallel momentum transfer respect to the beam axis $\left(p_{\perp} \approx 0\right)$ and the velocity of the formed fusion-like nucleus is not significantly perturbated by the following evaporation $\left(V_{\text {residue }} \approx V_{\text {fusion-like nucleus }}\right)$. In first approximation, the expe-

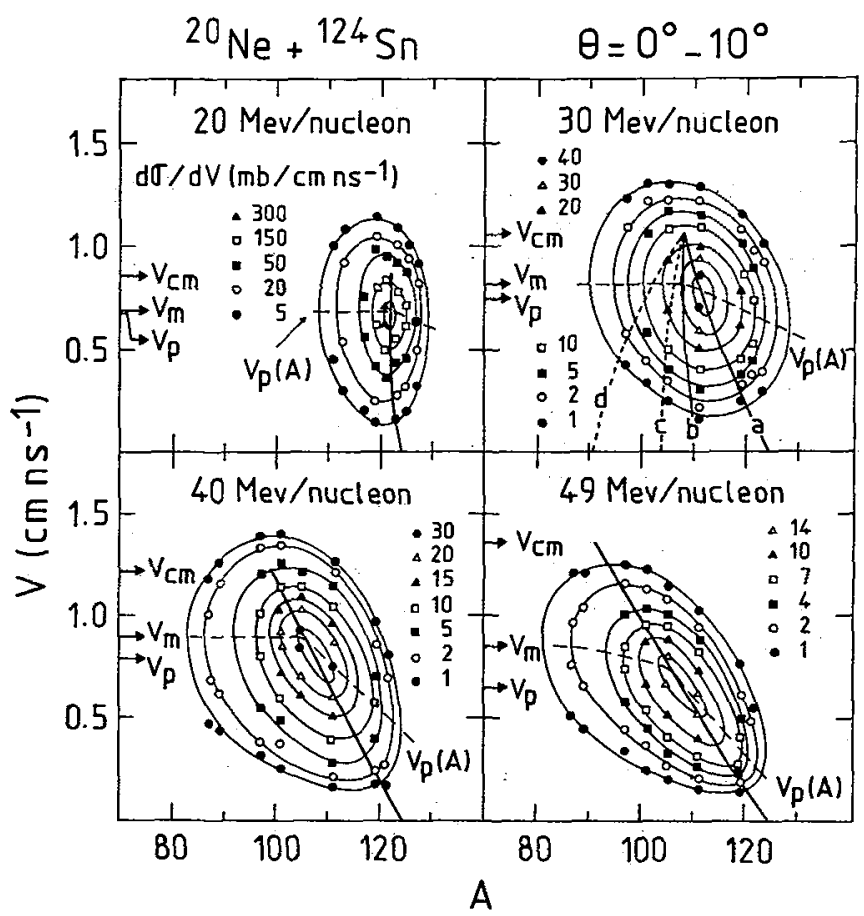

Fig. 1 - Mass-velocity spectra of residues emitted between $0^{\circ}$ and $10^{\circ}$ for ${ }^{20} \mathrm{Ne}+{ }^{124} \mathrm{Sn}$ at $20,30,40$ and $49 \mathrm{MeV} /$ nucleon. $V_{\mathrm{cm}}$ is the center of mass velocity; $V_{m}$ is the most probable velocity measured for the lower masses and $V_{p}$ is the most probable velocity of the distribution integrated over all masses. $V_{p}(A)(-\cdots)$ represents the evolution of the measured most probable energy as a function of mass ; see the text for the curves labelled $a, b(-)$ and $c, d(\cdots .--)$.

rimental results can be compared with $\mathrm{V}$ and $\mathrm{A}$ values calculated in simple incomplete fusion models where only a few parameters are used. To estimate the velocity $V$ and the mass $A$ of the residues, several assumptions can be done to realize the formation of the fusion-like nucleus.

In the "asymmetric hypothesis", a part of the projectile fuses with the totality of the target. The spectator nucleons of the projectile are emitted (as nucleons, clusters or unique quasi-projectile fragment) in the beam direction, with the projectile velocity $V_{p}$ (case labelled a) or with a part of the incident velocity (for example $80 \%$, case labelled b).

In the "symmetric hypothesis the target with the assumption that the same number of nucleons are escaping from the target as from the projectile. In this hypothesis, two reasonable situations have been treated for the spectator nucleons : in the first case they are emitted along the beam axis with their initial velocities, namely $V_{p}$, for the projectile nucleon (case labelled c) ; in the second case, it has been fixed that they are emitted with $80:$ of $V_{p}$ if they correspond to projectile nucleons and with $20 \%$ of $V_{p}$ for target 
nucleons (case labelled d). Assuming a reasonable value for the average energy carried away per evaporated nucleon (typically between 13 and $16 \mathrm{MeV}$ ), we can estimate the velocity $V$ and the mass $A$ of the residues from the momentum and energy conservation relations /3/.

Calculations of velocity and mass values have been done for the residues produced in the $20 \mathrm{Ne}+124 \mathrm{Sn}$ reaction at $30 \mathrm{MeV} / \mathrm{nucleon}$ in the four above mentioned cases and with a number of involved projectile nucleons varying from 0 to 20 . The results are drawn in figure 1 for the $30 \mathrm{MeV} /$ nucleon mass-velocity spectrum. It appears clear ly that the calculated curve labelled "a" fits quite well the experimental A,V distribution while the three other estimations disagree significantly.

To lighten the 20,40 and $49 \mathrm{MeV} /$ nucleon mass-velocity diagrams, the solid lines drawn correspond to values calculated in the frame of the "asymnetric hypothesis" and case "a" (fig. 1). One sees that the agreement between the experimental A,V distributions and the calculated ones is quite good.

In conclusion, for the $2 \mathrm{O}_{\mathrm{Ne}}+124_{\mathrm{Sn}}$ system, from 20 to $49 \mathrm{MeV} / \mathrm{nucleon}$, an incomplete fusion process where a part of the projectile fuses with the target while the spectator nucleons are emitted along the beam axis with the incident velocity, is in agreement with the experimental mass-velocity spectra of the residues observed between $0^{\circ}$ and $10^{\circ}$. Especially, the evolution of the distributions, with increasing incident energy, is remarkably well reproduced. Nevertheless, as the measurements have been made in the $0^{\circ}-10^{\circ}$ range, reactions with very small perpendicular momentum transfers have been predominantly selected and so, we cannot say that all incomplete fusion collisions lead to the emission of fast particules having the projectile velocity. One can only conclude that the "asymmetric hypothesis" is probably the best assumption for the whole of the incomplete fusion collisions.

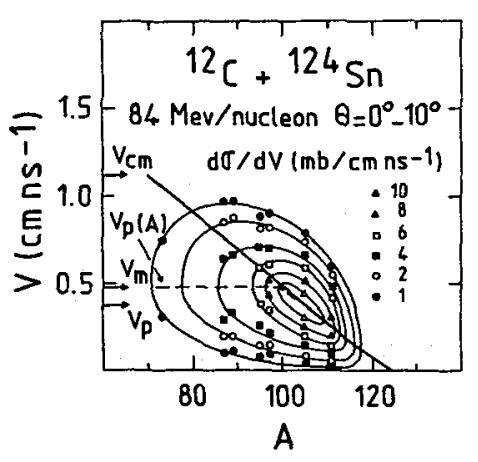

Fig. 2

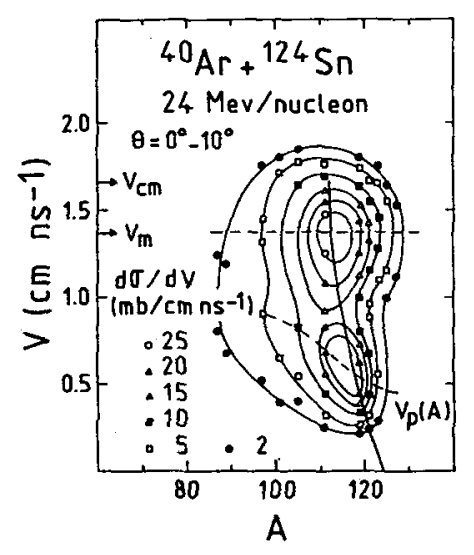

Fig. 3

Same as fig. 1 for other systems.

To check the applicability of this hypothesis, comparisons have been made for $A, V$ experimental residue distributions measured with various projectiles. Typical examples are reported for ${ }^{12} \mathrm{C}+124 \mathrm{Sn}$ at $84 \mathrm{MeV} /$ nucleon (fig. 2) and $4 \mathrm{O}_{\mathrm{Ar}}+{ }^{124} \mathrm{Sn}$ at $24 \mathrm{MeV} /$ nucleon (fig. 3). In both cases, the "asymmetric hypothesis" remains a good approach to fit the experimental mass-velocity spectra at small angles $\left(0^{\circ}-10^{\circ}\right)$. The comparison is specially interesting in the $4 \mathrm{O}_{\mathrm{Ar}}+124 \mathrm{Sn}$ case. Between 24 and $35 \mathrm{MeV} /$ nucleon, the velocity spectra exhibit two different components. From the comparison between A, V experimental results and "asymetric hypothesis" calculations, the situation appears more simple and mainly dominated by only one incomplete fusion mechanism. 


\section{REFERENCES}

/1/ Tsang,M.B. et al. Phys. Lett. 134B (1984) 169.

/2/ Lefort, M., IPNO/DRE 85-15 and ref. in.

/3/ Niffenecker, H. Nucl. Phys. A447 (1985) 533 C .

/4/ Lleres, A. et a1. Z. Phys. $\underline{\overline{A 312}}$ (1983) 177. 